\title{
HOW INTERNATIONAL COMPONENT STANDARDISATION AFFECTS SPECIFICATION AND DESIGN WORK IN INDIA
}

\author{
AMIT P. GOSWAMI \\ Resistors \& Capacitors Divn; Electronics Corporation of India Ltd., Hyderabad 500762, INDIA. $\dagger$
}

\begin{abstract}
The specification systems available to the Indian component manufacturers are discussed and the influence these have on the markets are examined. Quality control methods used to meet specifications are noted.

The influence of the Indian Government's pricing policy on the encouragement of indigenous production of components has an important effect, particularly with regard to the export and import of components. The differences that exist between component groups are outlined and it is shown that there are still important areas where overseas collaboration is encouraged.
\end{abstract}

\section{INTRODUCTION}

The rapid growth of the electronics industry in India has stemmed from the philosophy of self reliance. The setting up of the Department of Electronics and the Electronics Commission has resulted in channelling the development activities in various research institutes into studying commercially viable electronic products. The production of electronic goods in the country has increased from Rs 1800 million ( $\$ 240$ million) in 1971-72, to Rs 4110 million (\$541 million) in 1976, and has maintained a steady growth. This also includes exports of $\$ 36$ million to the international market ${ }^{1}$. The production figures when projected against the world market (Figure 1), show the Indian contributions to be small; but they seem respectable when compared with production from some individual countries within Western Europe. A special feature of the expansion of the electronics industry in India is a larger growth in the professional market which now has an internal share of $75 \%$ as against $40 \%$ a decade ago. Recent developments such as launching of the first Indian satellite, large scale control instrumentation for process controls, power generation and steel plants, developments of sophisticated medical and analytical tools, computers, etc., bear distinct testimony to the movement towards self reliance and the high degree of technology achieved in a short period.

The component industries too have not lagged behind in their efforts towards meeting the aspirations of the electronic designers and creating confidence in

tpaper written whilst on leave of absence to Department of Electronic \& Electrical Engineering University of Technology; Loughborough (UK) the use of indigenous components. Today, indigenous technologies have been developed for manufacturing metal and carbon film, wirewound resistors; carbon track and cermet potentiometers; tantalum and aluminium electrolytic, metallised polyester and

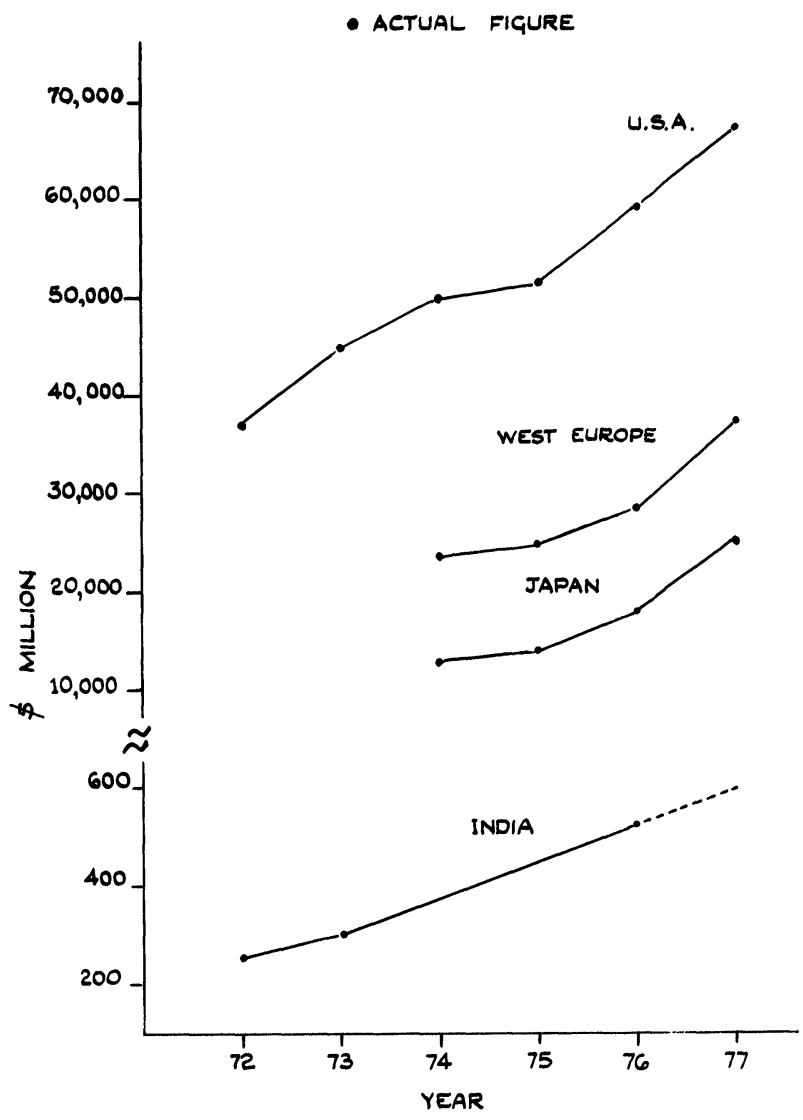

FIGURE 1 Production of electronic goods. 
ceramic capacitors; $\mathrm{Ni}-\mathrm{Cd}$ re-chargable batteries; various types of transistors and diodes; relays and connectors; ferrites etc. Small turnovers have also been achieved in thick film networks and hybrids, some types of I.C's, electronic grade ceramic substrates etc. These have been possible through fruitful researches at the Bhaba Atomic Research Centre, Electronics Corporation of India Ltd., Bharat Electronics Ltd., Central Electronics Ltd., the different laboratories of the Council of Scientific and Industrial Research and several leading universities in the country.

In many instances collaborations with manufacturers from abroad have been allowed although this has been played on a low key. Foreign collaborations have been permitted in those areas requiring a far higher degree of sophistication than can be immediately achieved through indigenous technology, when it is essential for the growth of the electronics industry. Collaboration has also been encouraged to bridge the gap between indigenous production capacities and internal demands. However, permission for collaboration would depend primarily on the needs of the country, ability to export and earn foreign exchange and also on the condition that sales within the country must not seriously affect the existing manufacturers ${ }^{2}$. Figure 2 summarises the present

COMPONENTS
(A) Resistors:
(a) Carbon film
(b) Metal film
(c) Wire wound
(d) Metal Oxide
(B) Potentiometers.
(a) Carbon track
(b) Wire wound
(c) Cermet
(C) Capacitors:
(a) Alumini um electrolytic
(b) Tantalum
(c) Metalilised polyester
(d) Ceramic
(D) Ni-Cd Batteries
(E) Connectors
(F) Relays and switches
(G) Soft ferrite
(H) Transistors (limited variety)
(I) Dlodes
(J) Integrated circuits "
ik) Hybrids

$$
\begin{aligned}
& \text { I// indicates nature of know-how } \\
& \text { Source: } \quad \text { Reference (2) and (3) }
\end{aligned}
$$

FIGURE 2 Production of some important electronic components in India. situation, and shows the components that are produced indigenously and/or with foreign collaboration.

\section{STANDARDS}

There are two independent standards organisations in India who have drafted specifications for all electronic components. These have been based on international standards such as MIL, BS, DEF and IEC. Combination of these international specifications have resulted in tight and respectable national specification standards.

(a) The Indian Standards Institute has drafted the Indian Standards (IS), which covers all components used in the consumer, professional and defence markets. Unfortunately, at present, this organisation has no component testing facilities to award approval certificates.

(b) The Electronic Components Standards Organisation (LCSO) was established to monitor the quality of the components used in defence. This organisation provided a yardstick for assessing the qualities through the Joint Services Specifications (J.S.S. - defence), which are again based on international military standards. The J.S.S. is basically the Indian military specifications. Interestingly both J.S.S., and Indian Standards for military requirements are similar. Table I shows as an example the typical tests used in J.S.S., for fixed resistors.

The LCSO has testing facilities in Bangalore and accords "Qualification Approval" certificates that are valid for a period of three years. During this time there should be no major change either in the manufacturing process or raw materials. Any such changes must be reported to LCSO for re-evaluation of the product. Reports of serious deviation from established qualities could lead to nullification of the approval.

Under these circumstances, established manufacturers prefer to obtain a LCSO approval as this would mean that the component.should easily meet the requirements of other less critical markets. Thus in India the term "approval" is often loosely referred to "military approval" (J.S.S.).

Not all component manufacturers have been able to obtain the "Qualification Approval" from LCSO. Only the larger companies and organisations with indigenous know-how and companies with foreign collaboration agreements have been successful in this attempt. The larger companies have succeeded in this venture through in-house research and development. Consequently the production of approved compo- 
TABLE I

Qualification/Approval Tests for Fixed Resistors (as per JSS 50401)

\begin{tabular}{|c|c|}
\hline Group & Title of Tests \\
\hline 0 & $\begin{array}{l}\text { Visual Examination } \\
\text { Dimensions (outline) } \\
\text { Weight } \\
\text { Resistance } \\
\text { Voltage Proof (one minute) } \\
\text { Insulation Resistance }\end{array}$ \\
\hline 1 & $\begin{array}{l}\text { Dimensions (detail) and Materials } \\
\text { Solderability } \\
\text { Robustness of Terminations } \\
\text { Impact (bump) } \\
\text { Vibration } \\
\text { Impact (shock) } \\
\text { Acceleration (steady state) } \\
\text { Temperature Cycling } \\
\text { Climatic }\end{array}$ \\
\hline 2 & Damp Heat (steady state) \\
\hline 3 & $\begin{array}{l}\text { Life (electrical) } \\
\text { Flammability }\end{array}$ \\
\hline 4 & $\begin{array}{l}\text { Overload } \\
\text { Mould Growth }\end{array}$ \\
\hline 5 & $\begin{array}{l}\text { Resistance to Soldering Heat } \\
\text { Resistance to Solvents }\end{array}$ \\
\hline 6 & $\begin{array}{l}\text { Voltage Coefficient } \\
\text { Temperature Characteristic of Resistance } \\
\text { Temperature Rise } \\
\text { Corrosive Atmosphere (salt mist) }\end{array}$ \\
\hline
\end{tabular}

nents is at present restricted to limited sources. In order to generate greater availability of these components, technical collaborations from abroad are being seriously considered on the lines mentioned earlier ${ }^{2,3}$. Import of components available indigenously is discouraged, although some relaxation is made with respect to specific qualities and requirements. Today, within the country, "Qualification Approval" has been accorded to carbon, metal film and wirewound resistors, some categories of potentiometers and trimmers, tantalum electrolytic, metallised polyester and ceramic capacitors, limited varieties of active devices, relays, connectors etc.

\section{MARKETS}

As in other western countries and in Japan, the Indian market for components consists of four major categories outlined below. a) Entertainment/Consumer. This sector produces a fourth of the total production of electronic goods in the country. In general, approvals are agreed between the manufacturers and customer, although in certain cases manufacturers are producing to entertainment grade specifications published outside India, (e.g. IEC). The indigenous component manufacturers have been able to meet the demands adequately.

b) Industrial/Professional. This embraces a wide range of products from simple measuring instruments to sophisticated controls and computer systems. Designers in this category are very conscious of the quality of components used in the circuit. Standardisation of components have helped them to assess the performance of indigenous products, and where suitable these have replaced the imported varieties. The use of approved components being made to fulfil the desired specifications gives extra confidence to the user to believe that a better performance will be obtained from the instrument. Designers have also realised that indigenous components, approved by LCSO, can adequately meet the needs for instruments meant for export, which are made to international specifications. To limit the manufacturing cost of the instrument due to the slightly higher prices of approved indigenous components, the designer selects components according to needs and instrument specifications. Where the requirements are critical only approved components are used.

c) Defence. All defence equipment must use components approved by the LCSO. These could be from indigenous sources or imported. Already a substantial number of the requirements are being met by approved indigenous components.

d) Aerospace. This industry has developed only recently and demands not only approved components, but established reliability. Although no indigenous manufacturer has publicly disclosed the reliability figures for their products, it is learnt that calculations for this data is now in progress ${ }^{4}$. The aerospace industry strongly favours the use of approved indigenous components should the reliability data be available. At present all "HI-REL" components are being liberally imported into the country.

\section{QUALITY CONTROL METHODS}

Quality control (QC) plays the most significant role in monitoring and maintaining standards of components. Although QC checks are done both by users and manufacturers of components, it is worthwhile to highlight the latter's approach. All leading approved 
component manufacturers have their own QC departments adequately equipped to carry out the necessary tests, and in most cases this department is independent of production ${ }^{4}$. The mulifunctional roles of the QC departments are.

i) Inward inspection of all raw materials

ii) Inspection of all outgoing components as per J.S.S.

iii) Long term evaluation of component parameters

iv) "On Line" inspection at various processing stages

v) Training of shop personnel in quality awareness

The concepts of statistical sampling techniques have been in vogue for many years. These are used both for inward as well as outward goods inspection.

Since manufacturers believe that raw materials, to a major extent, determine the quality of the component, very stringent and tight inspections are carried out during inward inspections with AQL's based on experience and process needs.

All outgoing components are subjected to QC tests for conformity to J.S.S. specifications. Acceptance levels for AQL's vary according to needs and faults can be classified as critical, major or minor ${ }^{5}$. In the case of major defects (for resistors these would be dimensions, insulation resistance and noise), AQL's of $\leqslant 1 \%$ for $95 \%$ level are used, and for minor defects (which for resistors would be TCR, electrical life up to $168 \mathrm{hrs}$, solderability, etc.), a level of $4 \%$ is normal. Critical defects are not usually defined by Indian manufacturers, but $100 \%$ checking for value, which is often classified as a critical defect, is a common practice and this is followed by the use of AQL's of $<1 \%$ at the final inspection stage.

Some processing areas have manual operations and $100 \%$ inspection becomes necessary, until as such time as the operators develop sufficient skill and quality awareness to introduce sampling.

Training of shop personnel in quality awareness is a major policy of reputed Indian manufacturers. This is essential in the Indian environment where a large semi-literate/literate labour force is employed in the component industry. This becomes even more important in areas where manual operations are predominant. To improve efficiency and quality for these lines, besides skill, it is necessary to motivate workers towards quality and cost consciousness. This has been found to be very effective through lectures and discussions at "shop-floor" levels.

Although short term tests are normally conducted for outgoing products, destructive and long term tests are done on samples selected from regular periods of production. Most manufacturers adopt identification codes which make it easy to locate defects during processing. However, to ensure the validity of all parameters, manufacturers undertake "Batch Acceptance Tests" as given in J.S.S. Since these tests are cumbersome and time consuming, a surcharge is generally levied over the normal price of the component for those that have been through these tests. Some component manufacturers also carry out special tests on request from customers, although these may not have any relevance to the normal specifications.

Reliability data on indigenous components are not available, but manufacturers undertake special screening techniques like "burn in", "thermal shocks", and other tests based on international specifications to weed out defective components and hopefully give a longer useful life to the component ${ }^{4}$.

On line stage inspections at critical processing areas are common to ensure both quality and yields. AQL's at these stages depend on processing parameters to meet the desired specifications.

Statistical Quality Control (SQC) techniques have been recently introduced by most reputed component manufacturers. Because of process secrecy, not much information is available on this subject, although manufacturers agree that incorporation of such techniques have helped immensely in improving quality and process yields ${ }^{6-8}$. The Indian Statistical Institute has opened several SQC centres to help manufacturers. These units coupled with R \& D activities, have been mainly responsible for improvements in the quality and manufacturing process of indigenous components.

Vendor rating has been another recent adoption by manufacturers and their customers to ensure optimum satisfaction in terms of quality, cost and delivery.

\section{PRICING POLICY AND EXPORT}

As mentioned earlier, import of components available indigenously is always discouraged and constraints on imports are effected through heavy import duties which may range from 40 to $130 \%$ over the actual costs. These strictures have been levied to encourage the growth and use of indigenous products. Consequently the "landed" price of imported components is normally higher than the indigenous product. However, indigenous manufacturers have tried as far as 
possible to maintain the selling costs close to the international market prices. Because of high costs of certain essential raw materials and most manufacturing machinery that has to be imported into the country, the average production costs of components within the country is higher than those of reputed manufacturers abroad. In this context one must also admit, with some reservations, that with indigenous technologies the process yields are not always optimum. Mass production by automation is the normal practice for reducing costs, but this has been found to be useful only in those areas where the process technology has been proved perfect. As a result, complete automation has been possible in only limited areas of manufacturing. Also the high costs of imported machines do not always increase profitability because the internal demands in the country may not be high enough. However, machines have been introduced in all areas where quality is a critical factor. On the other hand, the large and "fairly cheap" labour force available in the country is associated with smaller turnovers and less critical operations where workmanship would not adversely affect the quality of the component. Thus Indian manufacturers have had to strike a reasonable balance between manpower and machines to obtain optimum yields within working and technological constraints.

The effect pricing policy has on the availability of components meeting international and J.S.S. specifications, is of importance. It is hoped that all components made indigenously should meet J.S.S. standards and, as has been indicated previously, this is mandatory for Defence and Aerospace applications. If J.S.S. specifications cannot be met indigenously, then importation of components is allowed and the components carry a reduced import duty for defence equipments. Foreign collaboration is also encouraged in order to eventually create an indigenous availability of J.S.S. approved devices.

Export to international markets has been encouraged by the government, but only entrepreneurs with foreign technical collaborations have ventured into this area with creditable achievements. A major drawback for exporting approved components by manufacturers with indigenous know-how is the high production costs largely due to raw materials. Unless these are available indigenously at reasonable costs and good quality, manufacturers find it difficult at present to compete with the international market. In any case, in several spheres the internal demands of the country have to be satisfied as a priority.

In a recent survey made among component users in leading electronic industries in India ${ }^{9}$, the view was expressed that the passive component manufac- turers may meet the needs for resistors, capacitors and some grades of potentiometers during the next five years, but greater emphasis must be made on the availability of good quality mechanical components and the diversification of active devices. Also the price of existing approved components must be brought down to international rates in the national interest. Obviously these suggestions imply greater and more concentrated efforts in material science with intensive $R$ \& $D$ in component technology to constantly upgrade process capabilities, improve reliability parameters and reduce costs for production.

\section{CONCLUSION}

The growth of the Indian component business has been discussed relative to other areas and the method of setting standards for such manufacturing has been mentioned. The importance of Quality Control systems for the various markets has been examined and the Indian government policy for encouraging manufacture of indigenous components has been considered. The importance of indigenous components in the various market sectors is summarised in Figure 3. The proportion of indigenous components used in the different sectors is represented by the

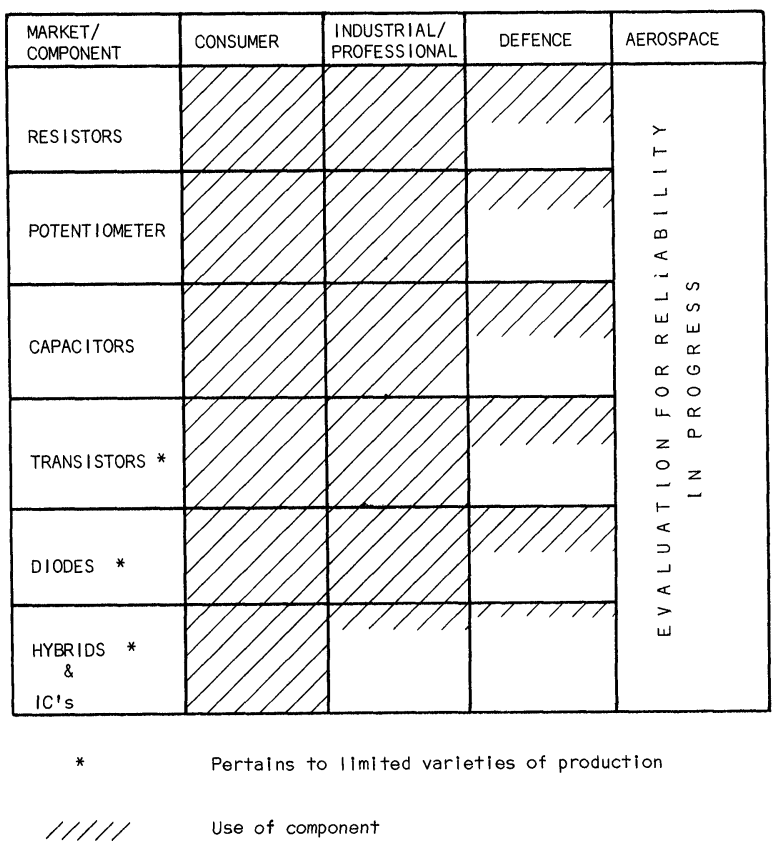

FIGURE 3 Use of indigenous components in the Indian market. 
amount of hatching in each of the boxes. Such a diagram also gives guidelines into areas where there is considerable scope for foreign participation.

\section{ACKNOWLEDGEMENTS}

The author is extremely grateful to Professor D. S. Campbell of the University of Technology, Loughborough, for his encouragement and suggestions in this work. He also wishes to thank Dr. A. Goswami of N.C.L. Poona, V. Philomin Raj of E.C.I.L., Hyderabad and the Electronics Commission, Delhi, for valuable information. Finally he is greatly indebted to the various leading component users and manufacturers in India for their prompt replies to the questionnaires sent to them by the author.

\section{REFERENCES}

1. "An overview of the electronics industry in India",
Information Planning and Analysis Group-Electronics Commission, New Delhi, India 1977.

2. "Guidelines for Industrial Licensing 1977-78: Electronic". Electronics-Information \& Planning (INDIA) 4 No. 8 pp. 767-786 (1977).

3. "Policy Back Ground Report on Passive Components". Electronics-Information \& Planning (INDIA) 3 No. 4 pp. 267-333 (1976).

4. Private communications from components manufacturers in India, August 1978.

5. H. Jackson and D. S. Campbell, Rad and Elec. Eng. 48, pp. 341-348 1978 .

6. Proceedings 6 th All India Conference on Statistical Quality Control, Hyderabad, December 1976.

7. A. P. Goswami, L. Saty anaryana, N. V. M. Sivaji, Electrocom. Sci. and Tech. 5, No. 2, pp. 77 (1978)

8. A. P. Goswami, M. Z. Ateeq, L. Satyanarayana and P. K. Basu ibid. 5, No. 3 pp. 141-147 (1978).

9. Private communications from component users in India, August 1978. 

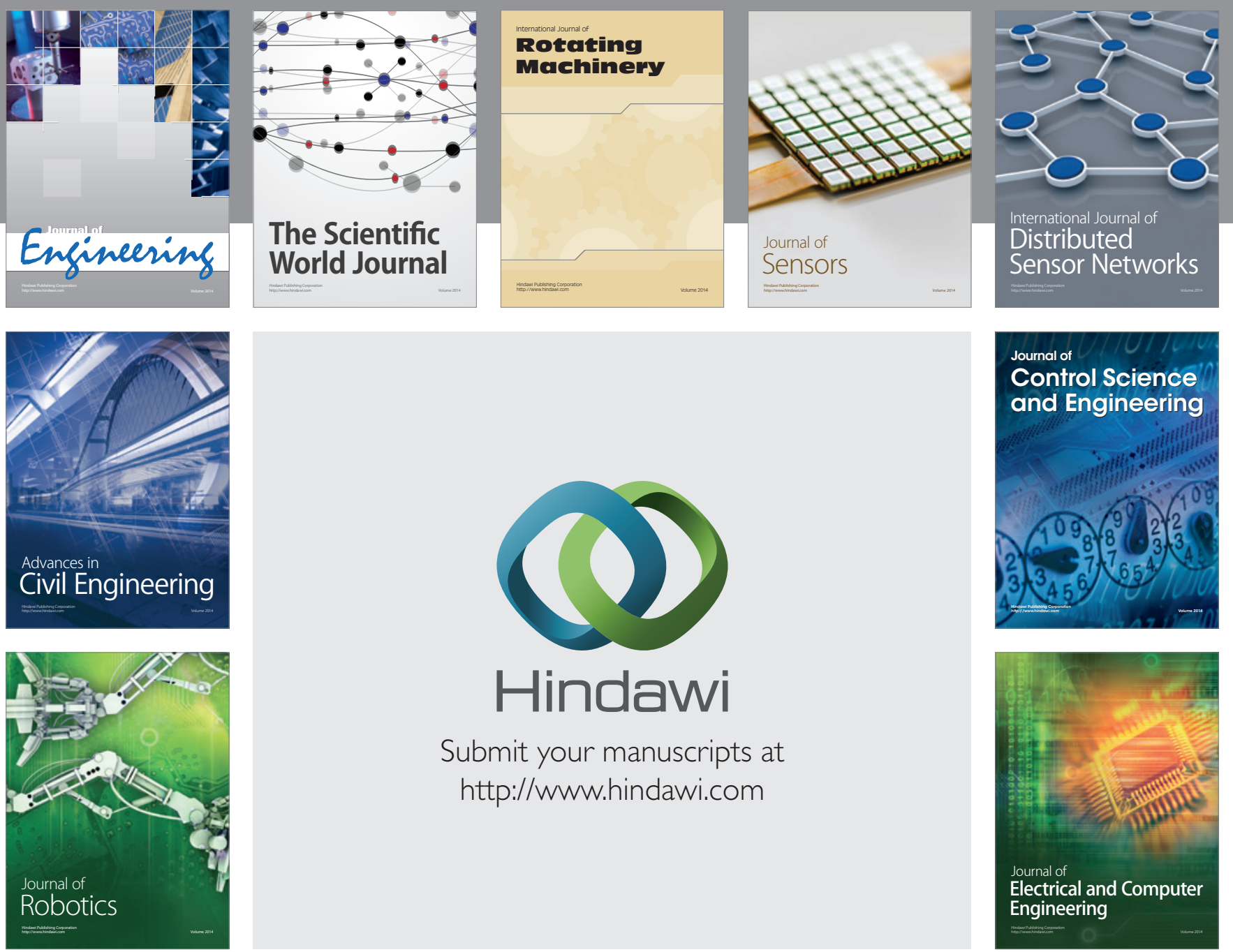

Submit your manuscripts at

http://www.hindawi.com
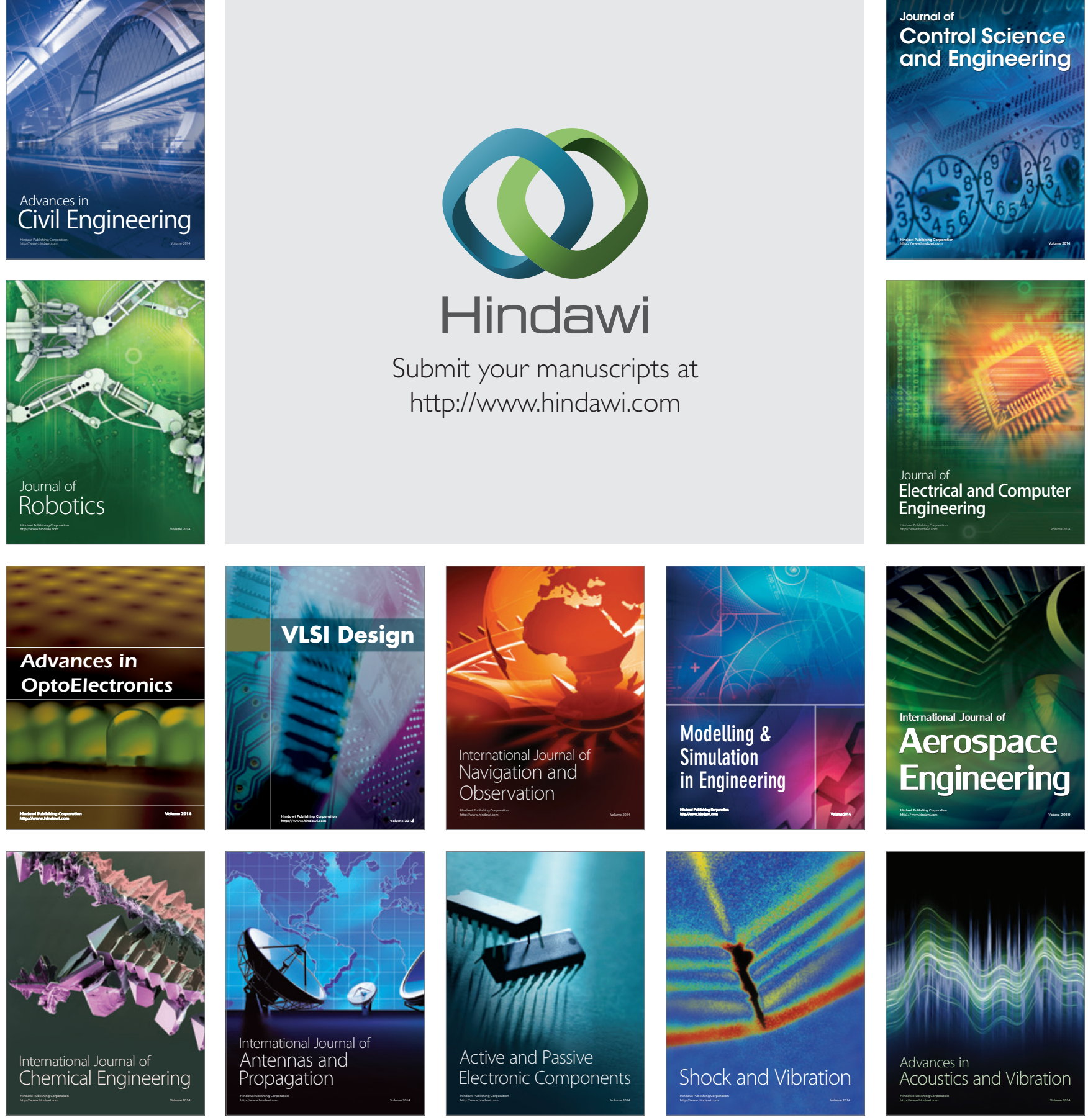